
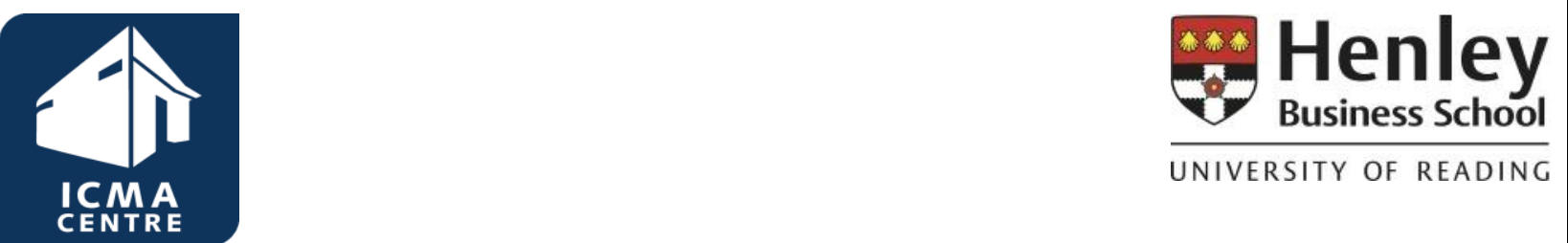

\title{
Is there a Gold Social Seal? The Financial Effects of Additions to and Deletions from Social Stock Indices
}

\author{
Konstantina Kappou \\ ICMA Centre, University of Reading \\ Ioannis Oikonomou \\ ICMA Centre, University of Reading
}

October 2012

ICMA Centre Discussion Papers in Finance DP2012-10

Copyright 2012 Kappou and Oikonomou. All rights reserved. 


\begin{abstract}
This study investigates the financial effects of additions to and deletions from two of the most well-known social stock indices: the Calvert social index and the MSCI KLD 400 index. By examining not only short-term abnormal returns but also trading activity, earnings per share and long-term performance of stocks that are involved in these events, we are able to shed new light on the characteristics of the "social index effect". We find that the addition of a stock to either index does not lead to material changes in its market price, whereas deletions are accompanied by negative cumulative abnormal returns of approximately $-1.5 \%$ in the short run that can reach $-14 \%$ six months after the event. Trading volumes for deleted stocks are significantly increased on the event date and operational performance of the respective firms deteriorates after their deletion from the social index. These findings are consistent with the asymmetric financial effects of corporate social performance that are connected to social index re-compositions.
\end{abstract}

Keywords: Social Index, Index Effect, Corporate Social Responsibility, CSR, CSP, Market Efficiency, Information Content Hypothesis, Exchange Traded Funds, Mutual Funds.

JEL Classification: G14, G32, M14

Dr Konstantina Kappou

ICMA Centre,

Henley Business School, University of Reading, Reading, RG6 6BA, UK.

Email: k.kappou@icmacentre.ac.uk

Dr Ioannis Oikonomou*

ICMA Centre,

Henley Business School, University of Reading,

Reading, RG6 6BA, UK.

Email: i.oikonomou@,icmacentre.ac.uk

*Corresponding author. We are very grateful to Calvert Investments and MSCI for the provision of the index data necessary to conduct this study. We would also like to thank Chris Brooks for his helpful suggestions. All remaining errors are the sole responsibility of the authors. 


\section{Introduction}

Corporate social responsibility and performance, sustainable business, corporate citizenship and governance, among a selection of many related terms, have become important concepts that have attracted the interest of academics, practitioners and policymakers alike. Within this area, the empirical relationship between corporate social performance (CSP) and firm financial performance (CFP) has been extensively examined. The main motivation for these investigations being that they can provide the basis for supporting that the implementation of socially responsible business practices is economically rational (if the relationship is positive) or, rather, detrimental to the bottom line of corporations (if it is negative). Both qualitative overviews of the literature (Margolis and Walsh, 2003; Renneboog, Ter Horst and Zhang, 2008) and statistical meta-analyses (Orlitzky, Schmidt and Rynes, 2003) are indicative of the methodological breadth and diversity of the individual studies and seem to point towards the existence of a mild positive link between the two concepts: firms that do good also do financially well (or at least do not do worse) and firms that are involved in social or environmental transgressions reap the economic repercussions of their actions (or inactions).

Interest in this research has increased in parallel with the financial markets' awareness of corporate social performance as a potentially important factor that can influence the riskadjusted returns of financial assets. Thus, socially responsible investing (SRI ${ }^{1}$ has also become more widespread. This is reflected in the constantly increasing number of SRI funds and the total assets under management which, in the US, have grown from 55 and $\$ 12$ billion (in 1995) to 493 and $\$ 569$ billion (in 2010) respectively in a matter of 15 years. The majority of this capital is managed by investment companies that take the form of mutual funds but there are also many exchange-traded funds, closed-end funds and alternative investment funds that are involved in SRI and apply environmental, social or governance (ESG) criteria in their screening processes. If we add the ESG assets that can be identified as being owned or administered by institutional investors (more than $\$ 2$ trillion), then it can be stated that nearly one out of every eight dollars under professional management in the United States in 2010 was involved in a strategy, which can be broadly placed under the umbrella of socially responsible investing. Equally impressive is the fact that although the number of funds in the hands of professional asset managers

\footnotetext{
${ }^{1}$ Broadly defined as a process whereby fund managers incorporate environmental, social and corporate governance considerations in the security selection process in an effort to maximize portfolio performance while respecting the social concerns of investors.
} 
significantly decreased during the period of the most recent financial crisis (2007-2010), the funds related to SRI have remained flat - (thus the market share of SRI effectively increased). ${ }^{2}$

Due to these evolutions, researching those aspects of the link between CSP and CFP that have significant and straightforward implications for financial markets and SRI is more topical than ever. This study focuses on one such aspect which has received a very small fraction of the attention of the relevant literature despite the fact that it has a direct association with the market's reaction to CSP information and is highly relevant to investor perceptions of CSP itself: the "social index effect", i.e. the price response that the announcement of an addition to or deletion from a SRI equity index causes to the underlying stock. Investigating these phenomena provides a unique setting for unveiling some of the finer characteristics of the relationship between CSP and CFP. By examining inclusions to and removals from SRI stock indices, which are highly visible public events, we can zoom in the magnitude of the market impact of thirdparty endorsements of firms' social performance. In addition, due to the relatively limited amount of indexed assets in the main socially responsible indices, any abnormal price performance observed during re-composition events could provide an unbiased signalling effect of the importance of ESG criteria within the asset allocation process. Furthermore, the fact that we look into short-term and long-term abnormal returns, trading volume and earnings per share for two different SRI indices and compare our results to the respective findings of the generic index effect literature allows us to provide answers to a series of more detailed inquiries such as:

1. Is there a symmetrical effect for additions versus deletions and if not, how can the asymmetry be explained?

2. Do these impacts differ from those reported in the literature on mainstream equity indices?

3. Relatedly, to what extent do the results from changes in social index composition reflect the relationship between corporate social responsibility and stock price performance rather than an index effect?

4. What are the key differences across the indices that we examine and to what can they be attributed to?

\footnotetext{
2 The data mentioned in this discussion are based on the 2010 "Report on Socially Responsible Investing Trends in the United States" created by the US Social Investment Forum, last accessed May, $16^{\text {th }} 2012$ at ussif.org.
} 
5. What is the long run impact of social index composition changes on the prices and volumes of the underlying stocks? Which of the theories that have been put forward to explain the index affect are most applicable in the context of social indices?

We anticipate that the answers we attempt to provide in these questions may be of considerable interest to all individuals that are involved in SRI and at least three key groups of institutional investors: hedge funds, managers of socially responsible funds, and index fund managers. Hedge funds operate within the mainstream equity markets around the times of index composition changes (e.g., of the S\&P500) in order to exploit the index effect by buying stocks that are announced to be entering the index, selling stocks that are announced to be removed, and closing out these positions shortly after the event. Entry into a social index fund may be expected to provide legitimacy to a firm's claim that it is socially responsible, and this effect would be in addition to the usual impacts from being included in any stock index. Finally, our research is of relevance to the managers of tracker funds who are desirous of knowing the optimal time to buy newly included stocks and sell newly deleted stocks in order to trade off tracking error (which is usually minimised by transacting immediately before the composition change) and adverse price movements (which are usually minimised by trading immediately upon announcement).

The remainder of this paper is structured as follows: Section 2 provides an overview of the index effect literature in general and the social index effect in particular. A description of the conceptual framework of this study and an overview of the alternative theories that have been used to explain different facets of the index effect are also given in this section. We provide a detailed account of the MSCI KLD 400 index and the Calvert social index characteristics as well as the methodological details of our empirical work in Section 3. The results of the various analyses we conduct are presented in Section 4. Section 5 contains a discussion of the key inferences that can be drawn from this study and outlines their potential practical significance for interested parties. 


\section{Related literature and candidate hypotheses}

\subsection{Previous findings from the index effect literature and hypotheses that can explain them}

The index effect, or the tendency for addition to or removal from a stock market index to cause changes in the prices or trading volumes of the underlying stocks, has been well documented for the stock market as a whole. The literature that investigates the index effect has grown simultaneously with the number and importance of index funds, institutional and individual investors who resolve to passive investing and index arbitrageurs. The advent of passive strategies and the perception that active managers do not beat the market led to the creation of the first index funds back in 1970s. Today, these funds have evolved into more liquid forms, usually referred to as exchange traded vehicles, the objective of which is to follow a particular benchmark. Institutions and private investors are more interested in indexing than ever before, because it offers lower management fees with negligible tracking errors.

The addition to (or deletion from) the index may be triggered by the firm meeting (or not meeting anymore) the relevant inclusion criteria or by a variety of different corporate events (delisting, bankruptcy, takeover and other). An important dimension that contributes to the magnitude of the index effect is the way that index re-compositions are announced in the market and consequently, the level of anticipation of the relevant changes. Despite the efficient market hypothesis (Fama, 1970) predicting that index re-compositions should not have any effect in stock $_{\text {prices }}^{3}$, significant price and volume changes connected to such events (mainly for the S\&P 500 index) have been observed in numerous studies. Consequently, a number of other theories have emerged to justify these results. The hypotheses proposed, refer to whether the effects on company stock price and volume performance are temporary or permanent, the new information component that, arguably, comes along with each announcement of addition or deletion and the investor behavior after the event.

The first theory relies on the price pressure assumption, which supports temporary price and volume effects as a result of index rec-compositions. Harris and Gurel (1996) reported a significant price increase of $3.13 \%$ on the date of an S\&P 500 inclusion, which was almost fully reversed after two weeks. Woolridge and Ghosh (1986) provided similar evidence by finding a

\footnotetext{
${ }^{3}$ Assuming that they have no impact on the discounted sum of the expected future firm profits accruing to shareholders.
} 
2.77\% price increase, while Arnott and Vincent (1986) reported a 2.91\% price increase on the date of addition and a $1.44 \%$ price drop on the date of deletion.

The second theory relies on the imperfect substitutes assumption that differentiates index member firms to non-member firms and contradicts to Scholes argument (1972), that stocks are not unique works of art and their demand curves are kept flat by arbitrage between perfect substitutes. According to this hypothesis, prices will change to eliminate any excess demand or supply in the market with no reversal, while trading activity will also change temporarily until the new level of equilibrium is reached. Shleifer (1986), Wurgler and Zhuravskaya (2002) and Morck and Yang (2002) examined the index effect and were in favour of this hypothesis. Tests for the imperfect substitutes theory require the assumption that the events are information-free. However, in 2003, Denis, McConnell and Ovtchinnikov proved that inclusion in the index was consistent with significant increases in earnings per share forecasts and significant improvements in realised earnings. Their results were in favour of the third theory that refers to the assumption of new information content. According to this hypothesis, index re-compositions are not information-free events, therefore the price effects on firm performance after the event period should be permanent. Jain (1987) also supported that the index effect has an information content, by reporting a $3.07 \%$ price increase for S\&P 500 additions and a $-1.16 \%$ for deletions, providing evidence that index inclusion was very valuable in terms of the future investment appeal of a company. Later studies by Dhillon and Johnson (1991) were also in favor of the information content theory.

The fourth theory relies on liquidity effects, which are mainly attributed to the increase of index funds. According to the liquidity cost theory, inclusion in an index is an event that promises a permanent increase in the stock's liquidity and therefore, prices and trading volumes shall both increase permanently to reflect this new advantage of the included stock. Edmister, Graham and Pirie $(1994,1996)$ were the first supporters of this hypothesis, finding permanent price effects after inclusion that did not reverse over time. In 2003, Hegde and McDermott provided evidence of a positive relation between stock prices and changes in liquidity, although it was uncertain whether the increase in firm value is attributed to better investment opportunities or to a potential decrease of the firm's discount rate upon inclusion.

The last theory that attempts to explain the index effect relies on Merton's theory (1987) about market segmentation and investor recognition. According to this hypothesis, investors know of only a subset of all stocks (in this case, only the index member stocks), hold only the stocks that they 
are aware of, and demand a premium (shadow cost) for the non-systematic risk that they bear. Chen, Noronha and Singal (2004) argue for the first time that inclusion in an index increases the overall investor awareness of the particular asset. As the stock becomes part of their portfolio universe, it is subject to stronger buying pressures and its required rate of return is permanently decreased. Since investors cannot be made unaware of a deleted stock, the price effects will not be symmetrically negative in the case of deletions from the index.

Given the above findings from previous literature, we anticipate that in the case of social indices, potential effects on company performance cannot be attributed to the price pressure, imperfect substitute and liquidity cost theories. We argue instead, that such events can produce strong signalling effects concerning a firm's level of corporate social performance (and consequently to future firm financial performance since the two concepts are related). We posit that the institutional seal of social responsibility that comes with the re-composition of social indices cannot be treated as an information-free event; therefore, the information content hypothesis is the best candidate for explaining any price and volume effects. Furthermore, although there might be asymmetries in the performance between added and deleted firms in the case of the social indices, these do not necessarily have to be consistent with the recognition hypothesis, since the nature of information revealed in the market is likely to undermine the shadow cost theory and impact the deleted firms at a higher degree than the added firms. An analytical discussion of the index effect within the framework of social corporate responsibility is provided in the following subsections.

\subsection{Social indices and reconstitution effects}

The rapid development of socially responsible investing into a significant and widely applied investment approach over the past two decades has motivated the construction of a great range of social indices ${ }^{4}$ (comprised of socially responsible stocks) and of social tracker funds ${ }^{5}$ that aim

\footnotetext{
${ }^{4}$ Schroder (2007) provides the details of 29 different SRI stock indices. At the time of writing, MSCI has more than 80 different ESG indices while the family of Dow Jones Sustainability Indices numbers 19 members; and these are just two ESG index providers.

${ }^{5}$ In the United States, "twenty-six exchange traded funds (ETFs) with $\$ 4.0$ billion in total assets were identified as incorporating ESG criteria. Although ETFs accounted for only 1\% of the total assets of all ESG investment vehicles, their assets have grown 225\% since 2007, the fastest of all registered investment vehicles"(Report on Socially Responsible Investing Trends in the United States, 2010, US Social Investment Forum, p.9).
} 
to replicate the performance of these indices. The performance characteristics and composition of socially responsible indices has been studied and compared to "conventional" equity indices (Schroder, 2007; Statman, 2006), the general consensus being that, on average, the two sets of indices have similar risk-return characteristics and highly correlated return patterns which, at times, also exhibit substantial dispersion between them.

Yet the studies examining whether there exists a socially responsible index effect are limited in both number and scope and although the literature on the index effect relating to mainstream indices is large, it is not clear whether the key findings therein also apply to socially responsible indices, which are typically both smaller in terms of assets following them and more specialised. It is perhaps also the case that investors may be more challenged in anticipating the future composition of social indices because of the fundamental additional criteria that the firm must meet in order to be be deemed socially responsible and enter the index, on top of meeting the other conditions of listing (based usually on firm size and the representativeness of the sector in which the firm operates).

To our knowledge, at the time of writing, the extant literature only numbers three studies. Becchetti, Ciciretti and Hasan (2009) employ the Domini 400 (now MSCI KLD 400 social index) for their analysis and find that stock deletions from the index produce negative short-term cumulative abnormal returns between $2 \%$ and $3 \%$ while no robust, statistically significant link can be detected when looking at additions to the index. These findings are echoed by Doh, Howton, Howton and Siegel (2010), who also examine short-term reconstitution effects and find that while additions to the Calvert social index do not incite positive market reactions, deletions lead to a significant average decline in equity prices of more than $1.5 \%$. On the other hand, Chow, Durand and Koh (2009) concentrate on the KLD 400 index but examine long-term price effects, and find strong evidence for positive buy-and-hold abnormal returns of additions, while the respective results for deletions are somewhat mixed.

It is clear from the paucity of evidence that much work remains to be done on socially responsible indices - in particular, in constructing an over-arching analysis. Since all three of these studies examine only abnormal returns over short or long periods and they do not consider other aspects of trading activity and performance, it is impossible to postulate with any reasonable degree of reliability the reasons why these abnormal returns occurred, what the implications are for finance theories and if the these findings are of direct relevance to practitioners. This study aims to considerably advance this emergent literature by providing 
comprehensive and robust evidence on whether the subsequent performance of firm stocks is affected by being added to or removed from a social stock index. By examining not only abnormal returns, but also trading volumes, and earnings per share, we plan to shed light on the theoretical explanations for any index reconstitution effects that are observed. This study is also the first in this area to simultaneously examine the social index effect for two indices and by doing so is able to inspect the difference in the magnitude of the effects for each index and, possibly, attribute this differential to the index characteristics and the respective inclusion/removal criteria ${ }^{6}$. In addition, we make use of datasets which cover more extensive periods of time for both indices, compared to previous studies, which adds to both the robustness and practical relevance of our work.

\subsection{Conceptual framework}

The generic literature that studies the index effect has put forward numerous hypotheses in order to explain the price reactions and turnover changes of stocks that are added to or removed from the index of interest. In addition, the extensive work that has been conducted on the empirical relationship between corporate social responsibility and firm financial performance has revealed a series of stylised facts that characterize this link. Since this study falls in the cross-section of the two strands of financial research, we attempt to highlight certain aspects of the CSP-CFP link that may somewhat differentiate the observed social index effect from the respective index effect of conventional stock indices.

The first observation we would like to make stems from the fact that corporate social performance is, admittedly, very hard to quantify. A wide range of measures have been employed to capture CSP: from the lines of prose dedicated to CSP in corporate disclosures, the amount of charitable contributions firms make, surveys and lists concerning the firms with the best reputation in terms of their business practices, to third-party social audits and their inclusion in social indices ${ }^{7}$. Due to the conceptual complexity that comes with CSR, along with the subjectivity and practical difficulties that can arise when attempting to measure it, stakeholders and investors interested in SRI are more likely to accept the CSR reputation concerning a

\footnotetext{
${ }^{6}$ Alternatively, in the case that the empirical results from both indices appear to be qualitatively identical and of similar significance, this will add convergent validity to the analytical framework.

7 A more detailed discussion of the various CSP metrics that have been used is provided by Margolis, Elfenbeim and Walsh (2009).
} 
corporation as legitimate when it comes through third-party institutional endorsement (Doh, Howton, Howton and Siegel, 2010). Such a "social seal" can be acquired in three ways:

1) A firm's participation in a list that is relevant to CSR (Fortune's "Most Admired" and "Best Companies to Work For" being two popular choices)

2) The ratings produced by the audits conducted by social ratings agencies and departments (the MSCI KLD database has been one of the most widely used in this respect)

3) Addition to a well-known social index with clearly established social criteria

Although each has its merits and there is validity in using any of them to infer a firm's CSR, reputation lists have been shown to be influenced by financial performance to a significant extent (Brown and Perry, 1994), while the results of third-party audits are not publicly available and the market's reaction to them cannot be accurately pinpointed around a specific date. Thus, we argue that additions to and deletions from well-established social indices can provide market participants with a strong and clear public signal concerning the social performance of the relevant firms. This signal has the potential to significantly influence the demand for these stocks (through individual and institutional investors) and corroborate the demand generated by ETFs. Although social indices refer to a narrower part of the market compared to some of the conventional indices where index effect have been observed (S\&P 500 being the most obvious case), there are still ample reasons to assume that such effects will also exist in their case.

A second issue has to do with the potential asymmetric impact of additions and deletions on abnormal stock returns. The index effect literature has provided empirical results which substantiate either 1) the existence of a qualitatively symmetric impact where additions to the index lead to positive abnormal returns and deletions from the index lead to negative abnormal returns (Arnott and Vincent 1986; Lamoureux and Wansley, 1987) or 2) the existence of an asymmetric impact where additions to the index lead to statistically significant positive abnormal returns but the abnormal returns related to deletions are less pronounced (Chen, Noronha and Singal, 2004).

However, when looking at social indices there is also the possibility there is an asymmetric effect of the exact opposite nature (non-significant abnormal performance for additions, negative returns for deletions). This can be based on empirical evidence that suggests that corporate social responsibility and corporate social irresponsibility affect a firm's financial performance in differing magnitudes. Wood and Jones (1995) make the observation that event studies making 
use of market-based measures of CFP reveal a trend for poor social performance to cause financial harm but do not provide evidence of financial benefits accruing from strong social performance. In addition, Meijer and Schuyt (2005) find that while consumers will boycott a firm if its CSP falls below some minimum threshold, high levels of social responsibility do not appear to increase product sales. On a more general level, it has been documented that "the economic impacts [of CSP] are more positive for issues reducing negative externalities than for issues generating positive externalities" (Lankoski, 2009, p.218) ${ }^{8}$. So if the signal generated by a stock's deletion from a social index is taken to mean not merely that the firm is less responsible than it was before but rather that it has been found to be involved in certain socially or environmentally controversial issues (whereas before it was not) then the financial impact can be theorised to be greater than that of an addition to the index.

Lastly, we argue that by studying the social index effect we can avoid the alleged endogeneity problems and simultaneity bias that may arise due to the bidirectional causality between CSP and CFP (Waddock and Graves, 1997). The phenomenon of interest takes place in three discrete steps: First the firm changes its posture towards society and the environment and materialises this change through its operations and interactions with stakeholders. Then the committee or organisation which is responsible for the composition of the index decides that the firm should be included to or removed from the index. Lastly, the market responds to the announcement of the decision of the committee. ${ }^{9}$ Because of this particular sequence, there appears to be a clear path that leads from social performance to index participation and the corresponding market performance (separated in distinct stages) and no obvious mechanism that suggests an inverse contemporaneous relationship that runs from financial returns to CSP.

\footnotetext{
${ }^{8}$ The discussion here follows Oikonomou, Brooks and Pavelin (2012).

9 There is also the possibility that due to leakage of information or the market's ability to forecast the decision of the committee, the effects of the reconstitution of the index are gradually incorporated to the prices of the stocks prior to the respective announcement.
} 


\section{Data and Methodology}

\subsection{Calvert social index and MSCI KLD 400 social index}

In order to conduct our analysis, we employ two of the oldest, most well-known and most frequently referenced US indices, whose constituents include stocks of firms that conform to criteria of social responsibility and are available to ESG investors for benchmarking: The Calvert social index and MSCI KLD 400 social index. Both indices apply a series of stringent criteria with regard to, inter alia, the firm's practices towards the local communities in which it operates, the natural environment, its employees, human right issues and its involvement in controversial industries. Further details of the ESG criteria for both indices are provided in the appendix.

Some additional clarifications concerning the inception, investment universe, non-ESG considerations, number of constituents, index reviews and the relevant announcements for both indices are warranted at this point. The Calvert social index was incepted in 2000. The 1,000 largest US firms, based on market capitalization are considered as potential index constituents. The stocks of the firms have to be included in the Dow Jones Total Market Index. Calvert also considers the economic sector weighting in maintaining the index. Quarterly reviews are conducted which take into account share adjustments, constituent changes in the performance of the ESG factors and sector weightings. Reviews held in September are also based on updated lists of the 1,000 largest US companies. The number of companies that are included in the Calvert social index has not remained stable over time. As of the $30^{\text {th }}$ of June 2011 the index numbers 656 constituents - a significant increase from the approximately 500 companies it included when it was launched. Because Calvert Investments is a manager of the Calvert social index as well as a variety of mutual funds, it is required under the Regulation Fair Disclosure of the US Securities and Exchange Commission to make press releases concerning the changes to the Calvert social index. Summaries of the announcements of the changes that occur to the index due to market actions and adherence (or lack of) to the ESG criteria can be found on the website of Calvert Investments.

The MSCI KLD 400 index (formerly known as the Domini 400 social index or FTSE KLD 400 Social index) was launched by KLD Research and Analytics Inc. in 1990. Since then, the acquisition of KLD by RiskMetrics and the subsequent acquisition of RiskMetrics by MSCI in June 2010 has led to the latter managing the index. MSCI KLD 400 consists of 400 companies with the underlying investment universe being the MSCI USA Investable Market Index (IMI). MSCI seeks to maintain a sector representation for the index with weights similar to that of 
MSCI USA IMI. There is also a size-segment representation with approximately $90 \%$ of the index being consisted of large cap companies, $9 \%$ of mid-cap companies and 1\% of small cap companies. Recomposition of the index take place on a quarterly basis (February, May, August and November) and the changes are implemented at the end of the month the review is held. Although deletions from the index (especially those caused by corporate events) may occur between index reviews, no additions to replace those firms will be made until the next scheduled index review. This effectively means that for a period of time the index will consist of less than 400 firms. Announcements of events related to changes in the index may be produced in a time interval that generally ranges from 2 to 10 days before the effective date (i.e. the date that the event actually occurs).

The Calvert social index has an ETF called Social Calvert Index Fund that tracks the index with a current capitalization of approximately $\$ 130 \mathrm{~m}$, whereas the MSCI KLD 400 index has an ETF called MSCI KLD 400 social index Fund, which is part of the i-shares family (Blackrock) and has a market cap of around $\$ 175$ million. Both funds run on expense ratios ranging between 70 and 90 basis points. $^{10}$

\subsection{Sample construction and calculation of abnormal returns}

Calvert Investments and MSCI have provided us with the lists of additions and deletions from the Calvert social index and the MSCI KLD 400 index respectively from inception until October of 2011. For Calvert, the earliest date for either type of event is June 1, 2000 and the latest is October 6, 2011. A total of 856 additions and 761 deletions are reported. For the MSCI KLD 400 index, the earliest date for either type of event is May 31, 1990 and the latest is July 14, 2010. The total number of observations is 267 for additions and 399 for deletions.

The initial samples are not completely free of any bias that could lead to erroneous statistical inferences. In particular, these samples may include firms that are in financial distress and are likely to go bankrupt or become takeover targets at about the same time that they are deleted from the index. Naturally such evolutions constitute confounding events and it is impossible to disentangle their influence on stock prices from that of the deletions from the social index itself. The renaming of a firm on the other hand is sufficient to lead to its deletion from the index (and its addition under its new name) but should generate only a very modest, if any, market response. Thus, we exclude all firms that their addition or deletion in either index is related to a merger,

\footnotetext{
${ }^{10}$ Numbers taken from http://www.calvert.com/fundprofile.html?fund=933 and http://us.ishares.com/product info/fund/overview/DSI.htm, last accessed June 25, 2012.
} 
acquisition, spinoff, bankruptcy, suspension or deletion of trading, change of name or ticker and other such corporate events. Additionally, in order to ensure the robustness of our estimates and avoid thin trading issues we impose a set of criteria for a firm to be included in our final sample. Specifically, we require that there are no missing values in the time-series of its price for the period starting 15 days before the event and ending 10 trading days (two weeks) after it, that there are no more than 25 missing values in aggregate for the next 375 days (approximately one and a half years) and that the average trading volume is greater than 100,000 shares over a period of one year before the event. Lastly, in order to avoid the effects that extreme values will have on our results, we do not include in our calculations of daily average abnormal returns (AARs) any firm-day observations with an absolute value of $20 \%$ or more. This last criterion leads to a small dynamic variability in the overall number of firms that are used in the calculation of AARs. There requirements (along with data availability of prices, trading volumes, earnings per share and market values for each firm - obtained by Thomson Reuters Datastream) lead to final samples of approximately 365 additions and 177 deletions for the Calvert social index and 201 additions and 77 deletions for the MSCI KLD 400 index.

In our analyses, we employ simple daily returns calculated on a closing price basis. Daily observations are consistent with the method used by previous research and due to the large sample size, the problem of non-normality for daily data (Brown and Warner, 1985) is not an issue. Previous studies on index effect have employed a multitude of different methods for calculating abnormal returns for the duration of the event window of interest. The most frequent choice among them is the market-model: a parsimonious one-factor model that adjusts returns according to the level of systematic risk. Although more complex models have also been used to account for additional factors that may be important determinants of stock returns (Fama and French, 1992; Carhart, 1997), it has been noted that "In practice the gains from employing multifactor models for event studies are limited. The reason for this is that the marginal explanatory power of additional factors beyond the market factor is small, and hence there is little reduction in the variance of the abnormal return." (Campbell, Lo and MacKinlay, 1997). Thus we elect to employ the market model in this study. In order to estimate the model parameters, we use a post-event period to count for potential selection criteria effects. Jain (1987) and Edmister, Graham and Pirie (1994, 1996) argue that the parameter estimates derived from the period before the event will be biased, since the firms are likely to have performed well before their inclusion in the index. In other words, they may well have been included in the index precisely because of their relatively good past performance. Copeland and Mayers (1982) have used a post-inclusion estimation period to confront the selection bias in their study for measuring the abnormal performance observed 
from the announcement of stock rankings of Value Line Investments. Concerning event studies for S\&P 500 index changes, Denis, McConnell, Ovtchinnikov and Yu (2003) also used a postinclusion estimation period.

The linear specification of the market model for any security $i$ at time $t$ is:

$$
R_{i t}=a_{i}+\beta_{i} R_{m t}+\varepsilon_{i t}
$$

where $R_{i t}$ and $R_{m t}$ are the period- $t$ returns on security $i$ and the market portfolio, respectively, $a_{i}$ is the return when the market portfolio returns is zero, the $\beta_{i}$ is the sensitivity to each source of risk, and $\varepsilon_{i t}$ is the zero-mean disturbance term. We use S\&P 500 as a proxy for the market portfolio. S\&P 500 is the most closely followed US stock index and is widely considered to be representative of the US economy as a whole, having approximately $75 \%$ coverage of US equities. ${ }^{11}$ Model coefficients are estimated from a period of 250 days, starting 126 days after the event and ending 375 days after the event. We choose this period as we also require a lengthy observation window (which starts 15 days before the event and ends on 125 days after the event) that does not overlap with the estimation window for the purposes of investigating long-term stock performance.

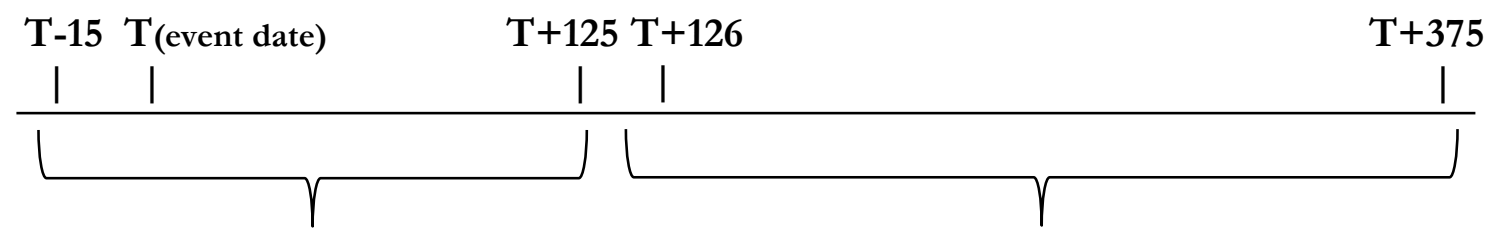

\section{Long-term observation window}

Estimation window

The abnormal return for each stock will thus be given by ${ }^{12}$ :

$$
A R_{i t}=R_{i t}-\hat{a}_{i}-\hat{\beta}_{i} R_{m t}
$$

The next step is for the abnormal returns calculated for every stock to be averaged against the total number of announcements $N$ for each day of the event window of interest:

$$
A A R_{t}=\frac{1}{N} \sum_{i=1}^{N} A R_{i t}
$$

and lastly for these average abnormal returns to be summed over the entirety of the event window (from day " 1 " to day " $T$ ") in order for the cumulative average abnormal returns to be calculated:

\footnotetext{
${ }^{11}$ http://www.standardandpoors.com/indices/sp-500/en/us/?indexId=spusa-500-usduf--p-us-l-- last accessed June, $5^{\text {th }} 2012$.

${ }^{12}$ The following part of this sub-section follows Kappou, Brooks and Ward (2008).
} 


$$
C A A R_{1, T}=\sum_{i=1}^{T} A A R_{t}
$$

To test the statistical significance of the AARs and CAARs, two-tail $t$-tests are performed that are defined as follows. For testing AARs:

$$
t-s t a t=\frac{A A R_{t}}{\hat{S}\left(A A R_{t}\right)}
$$

where $\mathrm{AAR}_{t}$ is the average abnormal return at time $t$ and $\hat{S}\left(A A R_{t}\right)$ is the standard deviation of the average abnormal returns over the estimation period (from day 1 to day $T^{\prime}$ ), given by the following formula:

$$
\hat{S}\left(A A R_{t}\right)=\sqrt{\frac{1}{T^{\prime}} \sum_{t=1}^{T^{\prime}}\left(A A R_{t}-\overline{A A R_{t}}\right)^{2}}
$$

For testing CAARs:

$$
t-s t a t=\frac{C A A R_{1, T}}{\hat{S}\left(A A R_{t}\right) \sqrt{n}}
$$

where $\mathrm{CAAR}_{1, T}$ is the cumulative average abnormal stock return from day " 1 " to " $T$ " and $n$ is the number of days between " 1 " and " $T$ ". The null hypothesis is that the AARs and CAARs should be zero.

\subsection{Abnormal trading volume}

We examine volume data before and after the event period. If events are anticipated, significantly increased trading activity should be expected before the index re-composition event takes place. Volume data can give information about the timing of purchases caused by index funds and other institutional investors, as well as about the demand that may have been caused by arbitrageurs.

Abnormal volume performance was estimated using volume ratios, a method also employed by Harris and Gurel (1986) and Beneish and Whaley (1996). The average relative stock-to-S\&P 500 volume ratios were estimated over a period of 12 weeks (60 trading days) before the event period, considered as the base volume for each added stock. The 60-day period started 120 days before the event and ended 60 days before the event in order to avoid biases of inflated volumes figures due to potential market anticipation of the index re-composition. They were then compared with the daily stock-to index ratios observed during and after the event period. The null hypothesis is that the mean volume ratio across all firms for each day $t$ of the event period 
should equal one. If the null is not rejected, then there is no significant abnormal volume on that day. The formulas for calculating volume ratios are given below:

$$
\begin{aligned}
& \overline{B V R_{i}}=\frac{1}{60} \sum_{t=E D-120}^{t=E D-60}\left(\frac{V_{i t}}{V_{m t}}\right) \\
& V R_{i t}=\frac{V_{i t}}{V_{m t}} \div \overline{B V R_{i}} \\
& M V R_{t}=\frac{1}{N} \sum_{i=1}^{N} V R_{i t}
\end{aligned}
$$

where, the base relative volume ratio $B V R_{i t}$ is the average stock-to-index trading volume in the 12 weeks before the start of the event window, $V_{i t}$ and $V_{m t}$ are the trading volume of each stock and the corresponding S\&P 500 volume at each day $t$ of the event window respectively, $M V \mathrm{R}_{t}$ is the mean volume ratio across firms at each day $t$ of the event window and $N$ is the number of firms in the sample.

The significance of volume ratios is measured by the t-mean test defined as follows:

$$
t-\text { mean }=\frac{M V R_{t}}{\operatorname{stdev}\left(M V R_{t}\right) \sqrt{N}}
$$

where, $M V \mathrm{R}_{t}$ and $N$ as defined above. 


\section{Results}

\subsection{Stock Price Performance}

\subsubsection{Short run performance and cumulative average abnormal returns}

Tables I and II report the average abnormal returns for additions and deletions to the Calvert social index and the MSCI KLD 400 index respectively for the period starting 10 days before the re-composition occurs and ending 15 days after it. No particular pattern emerges when looking at the abnormal returns of the additions samples for both indices. Their values are quite low, generally statistically insignificant and their signs change from day to day within the observation window. The picture is more clear when focusing on the average abnormal returns of the deletions samples where the majority of the statistically significant values are negative and close to $-1 \%$. In the case of Calvert this results are mainly observed within the first 10 trading days post-event whereas in the case MSCI KLD 400 index the only significant result is a negative abnormal return of $-0.69 \%$ which occurs on the event date.

Tables III and IV report the cumulative average abnormal returns connected to the recomposition events for both short-term and long-term observation windows for the two indices. Overall, the cumulative performance of firms added to either index is actually slightly negative in the short-term after the event but this effect is somewhat counterbalanced by the positive returns which these firms reap shortly before their inclusion (an observation would be taken to mean that the market may have a modest ability to predict some of these inclusions a few day before they happen). However, all these results do not pass the standard statistical tests. Stocks deleted from either index have CAARs approximately equal to $-1.50 \%$ for the first three weeks after the event but still these findings are not statistically significant. What is more impressive is the fact the six months after the firms have been deleted from the social indices, the CAARs remain negative in the case of the Calvert social index $(-1.39 \%)$ and further accumulate to a total of $-14 \%$ in the case of the MSCI KLD 400 index (a result which highly economically and statistically significant.

Taking all the above results into consideration, it appears that there are no significant short-term price pressures related to stocks added in the two social indices. The same can be said about deleted firms although there is qualitative support in favour of the existence of negative abnormal returns. Given the modest market capitalizations of the ETFs of both indices (less than $\$ 200$ million) it appears plausible than there are no material institutional price pressures 
placed on the indices during re-composition events. On the other hand there is stronger support for a negative long-term price effect connected to firms being deleted from either index. Not only the cumulative performance remains negative after several months, but in the case of the MSCI KLD 400 index, the negative effect is significantly reinforced.

\subsubsection{Additional analyses}

This apparent asymmetry in the financial effects connected to social index re-compositions (no significant result for additions, negative and significant in the long-term for deletions) prompts us to do some additional exploratory analyses. In particular, we are attempting to investigate whether there is some variability in the post-event financial performance of firms added in the sample that is not immediately visible.

We separate our samples of firms added to each index into three tertiles according to their market capitalization and repeat our main analyses. Figures 1 and 2 illustrate the dynamic evolution of CAARs for the sub-samples of firms of different sizes for the Calvert social index and the MSCI KLD 400 index respectively. It is clearly noticeable that with time there is a divergence in the performance of firms added to the social indices, with larger firms significantly outperforming medium and small firms. This observation is true for the entire post-event period with regard to the firms added to the Calvert social index and applies to the latter half of the long-term post-event observation window for the MSCI KLD 400 index.

It appears that in the long run, relatively larger firms might be of greater importance when added to a social index. One reason could be that these firms are able to attract more significant institutional demand that arises not only from index funds but also, equity mutual funds, pension funds and insurance funds. A more diverse institutional appeal would create material buying pressures and increase the prices for these stocks in the long-term. In addition, relatively higher transaction costs for the smaller firms added to either index could also reduce the potential demand that they are subject to compared to that of the larger constituents.

\subsection{Trading volume performance and effects on earnings per share}

\subsubsection{Trading during index re-composition announcements}

According to previous findings, there are two main parties that are involved in trading index recompositions. The first one represents index fund managers, the mandate of which is very 
specific. Passive trackers will wait until the closing auction of the event date to rebalance their portfolios and avoid tracking errors. Brooks, Kappou and Ward (2010) showed that in the case of the S\&P 500, the volume levels on the event date were almost 16 times higher than normal and most trading activity was concentrated towards the last 5 minutes of the trading day, indicating that index fund managers were more concerned with tracking error than with firm performance during the event window. The other party involved in index re-compositions represents the arbitrageurs, and in cases where index changes are preannounced, they will trade on the first date after announcement by buying (selling) the added (deleted) stock and close out the position on the event date, when index fund managers are entering the market.

In the cases of the Calvert and MSCI KLD 400 indices we anticipate any abnormal trading activity to concentrate on the event date and a few days after. Any abnormal trading before the event could provide evidence of anticipation of the index changes by analysts who follow the relevant stocks and who closely monitor the rankings of socially responsible companies.

\subsubsection{The effects of social index re-compositions on trading volume}

Table $\mathrm{V}$ presents the volume ratios of the firms added to and deleted from the Calvert social index starting from two weeks before the event until three weeks after. The volume ratios remain very close to unity until the event date. On the event date the trading volume becomes 1.32 times greater than normal for the average added stock and 1.33 times than normal for the average deleted stock. The volume ratio reaches its peak at the end of the first week after the event (1.85 times higher than normal for additions and 2.27 times higher than normal for deletions). Although volume figures continue to be consistently above one, they remain statistically insignificant throughout the short-term event period. Figures 3 and 4 depict the long run evolution of the volume ratios for the added and deleted stocks respectively, showing that they remain fairly stable for at least a period of one year after the event date. We would like to note that Figures 3 and 4 appear to mirror one another because the vast majority of the additions and deletions from the Calvert social index occur on the same dates: at the annual reviews of the index held in September. The spikes observed in both graphs more than 40 days after the events are statistically insignificant and are devoid of economic interpretation as they are attributed to a few outliers. We can therefore document fairly temporary pressures in trading volumes during the first few weeks, which are not statistically significant and certainly with no long-term effects.

The results from the MSCI KLD 400 index are similar in nature but stronger, especially for deletions (just as in the case of abnormal returns). Table VI shows that volume ratios for both 
added and deleted firms for the same observation period as discussed above. Although the figures for the period before the event are not significant in the case of additions, the stocks of deleted firms are characterised by significant trading activity throughout the two-week period before the event date, possibly providing evidence of anticipation of the coming event. On the event date, the average volume ratio of the added stocks is 1.83 times higher than usual which is insignificant, whereas the average volume ratio of the deleted stocks is 4.48 times higher than normal which is highly significant. Both of these numbers are the peaks of the trading volume ratios for both samples of the MSCI KLD 400 index. The abnormal volume activity remains significant for a period of almost two weeks after the event, but only for the deletions sample. This may indicate that the market appears to be concerned more with deletions rather than additions when it comes to information connected to changes in the level of corporate social performance of the firms. With regards to the long run performance of the volume ratios, we can see that the trend reverses and trading volumes decrease after the event dates (Figures 5 and 6). From all the above findings, we conclude that there is a short-term increase in trading volumes surrounding the date of social index re-compositions. It also seems apparent that there is more abnormal trading activity around deletion events which again is stronger in the case of the MSCI KLD 400 index.

\subsubsection{Index rebalancing and operational performance}

The S\&P 500 index effect literature provides theories that contradict one another when it comes to the effects of index membership on company performance. Malkiel and Radishich (2001) find no evidence of increase in company valuation after inclusion, by using a discounted cash flow model that was applied to a sample of index member and non-index member firms. Morck and Yang (2002) on the other hand provide evidence that index inclusion is associated with significantly higher company valuation, by observing the firm's Tobin q ratio. A re-composition of the Calvert and MSCI KLD 400 index can provide signals of changes in the level of a corporation's social performance, which may consequently affect the future economic performance of the relevant stocks. Indeed, the majority of the CSP-CFP literature at the firm level suggests that there is such a positive connection although its characteristics are debated (Margolis and Walsh, 2003; Orlitzky, Schmidt and Rynes, 2003). The theorised change in a firm's valuation is consistent with the information content assumption, on the basis that the seal of social responsibility represents a "certification effect" that could lead to improved financial performance. 
We examine firm earnings before and after the event of additions to and deletion from both Calvert and MSCI KLD 400 indices. The variable we employ is Earnings per Share (EPS) obtained from Thomson Reuters Datastream. The pre-event earnings per share are computed for each firm using a period of one calendar year before the re-composition event (average of earnings over four calendar quartets). Accordingly, the post-event earnings per share were computed for each firm using a period of one calendar year after the event. A simple equality of means test is performed to identify whether changes in earnings per share are statistically significant.

Tables 7 and 8 present the results for the Calvert and MSCI KLD 400 indices respectively. The patterns of EPS performance are similar for both indices. In the case of additions, the level of earnings per share for the Calvert member firms increased by $15.6 \%$ (from $\$ 2.24$ to $\$ 2.59$ ) whereas for the MSCI KLD 400 index member firms it increased by $5.96 \%$ (from $\$ 1.37$ to $\$ 1.45$ ). In the case of deletions, earnings per share fell by $21.2 \%$ (from $\$ 1.39$ to $\$ 1.09$ ) for the Calvert constituents and by $6.5 \%$ (from $\$ 2.20$ to $\$ 2.06$ ) for the MSCI KLD 400 index member firms. An interesting point that arises from the above analysis is that the asymmetry of results between additions and deletions remains, as in the case of abnormal returns and trading activity. The changes in earnings per share are greater in magnitude for the deletions sample for both Calvert and MSCI KLD 400 indices.

Hence, the above results are in line with our expectations about the effect of the social (ir)responsibility factor on company performance although the differences are not statistically significant. It appears that the detriments of social irresponsibility are more impactful than the benefits that come with the gold seal of social responsibility. 


\section{Discussion}

This study extends the extant CSP-CFP literature by providing comprehensive analyses and interesting findings on whether the financial performance of firm stocks is affected by being added to or removed from a social stock index. Our investigation of abnormal returns, but also trading volumes and earnings per share, allows us to connect our results with the theoretical explanations for index reconstitution effects that have been put forward by the scholars of this field and assess the practical usefulness of these results. Our use of data for two different social indices and for lengthy periods of time enhances the robustness of our results. It also allows us to consider the impact that index characteristics (number and size of constituents) have on the financial effects of index re-compositions.

The essence of our findings is that the inclusion of a firm in either the Calvert or the MSCI KLD 400 social index does not produce economically substantial or statistically significant, short-term or long-term abnormal returns. However, the deletion of a stock from either index results, on average, in negative cumulative abnormal returns of approximately $-1.50 \%$ within 15 trading days after the event. These results are in line with the findings of Becchetti, Cicciretti and Hasan (2009) for the MSCI KLD 400 index and Doh, Howton, Howton and Siegel (2010) for the Calvert social index. In addition, the long-term financial performance of the deleted stocks is also negative for both indices, with the firms that are removed from MSCI KLD 400 index experiencing an especially strong negative performance which accumulates to $-14 \%$ in matter of six months after the event.

Overall, there appears to be an asymmetric social index effect whereby deletions are connected with negative abnormal performance (a result which becomes stronger with time) but additions do not lead to any significant change in market prices. From the perspective of the generic index effect literature these findings do not fully adhere to any of the hypotheses that have been employed in the past. Still, there are many empirical and conceptual aspects surrounding these events which can explain these findings to a substantial extent. First of all, we have shown that although the results produced by the entire sample of firms added to either index are insignificant, further investigation reveals that there is significant variability in the long-term performance of these stocks according to their market capitalization and that, evidently, larger firms do reap positive abnormal returns six months after the event. This can be attributed to stocks of larger firms experiencing lower transaction stocks and being potential buying targets of 
a much more diverse group of investors. Therefore, there may still be a positive effect from additions to social indices, albeit only for larger firms.

Secondly, the asymmetric impact of these events is fully aligned with a great deal of empirical work in the CSP-CFP literature (Wood and Jones, 1995; Meijer and Schuyt, 2005; Lankoski, 2009; Oikonomou, Brooks and Pavelin, 2012), which suggests that corporate social responsibility and corporate social irresponsibility are not the flip sides of the same coin and the negative financial impact of the latter is, ceteris paribus, stronger than the positive financial impact of the former. Thus, because a stock's deletion from a social index can be interpreted as a strong, highly visible signal produced by an independent institution that the firm has been involved in some kind of a social or environmental transgression, it is plausible to find that its financial effects are greater than those of additions to the index (which is a signal for the firm being a strong social performer). This information content effect, which is asymmetric, is also supported in our study by the results of our additional analyses. We note an increase in trading volumes surrounding the event dates (particularly strong in deletions) which is reversed in the year following the events. Furthermore, we document an increase in the earnings per share for the firms added in either index and a decrease for the firms deleted, with the latter being more substantial than the former.

Thirdly, as Doh, Howton, Howton and Siegel (2010) also note, there may be a behavioural element involved in the explanation of the differential index effect. In particular, Baumeister, Bratslavsky, Finkenauer and Vohs (2001) have shown that individuals tend to react more intensely to negative rather positive new information. Similarly, it has been shown in the literature of financial economics that "losses and disadvantages have greater impact on preferences than gains and advantages" (Tversky and Kahneman, 1991 p. 1039), a sort of loss aversion utility theory which is also in line with our findings. Although these cognitive biases could also be used to explain, in part, why we document negative short run abnormal returns associated with deletions and no material price changes for additions, they, admittedly, do not explain the respective differences in long-term stock performance connected to the two types of events.

Although we have documented negative abnormal returns associated with deletions from both indices, our findings are stronger in the case of the MSCI KLD 400 index. We believe that this is relevant to the differences in the characteristics of the two indices. The MSCI KLD 400 index has been comprised by 400 stocks since its inception whereas Calvert social index has had more constituents from the very start and has, at the time of writing, more than 650 in total. Taking this into account, we would expect the signalling effect emanated from a deletion of a firm from 
the "smaller" index (MSCI KLD 400) to be stronger than that of a deletion from the "larger" index. On a related issue, the average market capitalization of the constituents of the Calvert social index is smaller than that of the constituents of the MSCI KLD 400 index. It has been argued that stakeholders recognise the challenges of limited resources (Tilley, 2000) and significant viability issues with which small and medium size firms are faced, combined with the minor individual impact of their social/environmental practices, and thus do not take action against certain types of irresponsible corporate behaviour. Thus, it is plausible that deletions from the index including, on average, larger firms create a greater market response compared to the opposite.

In spite of our best efforts to create a comprehensive analytical framework concerning the social index effect, there are a number of ways in which the literature can be expanded. First of all, the modest market capitalization of the ETFs for both indices and the absence of a derivatives market for either of them can help to explain why our study does not, for the most part, document significant short-term price pressures surrounding index re-compositions which can be attributed to the demand of these indices as packaged products. However, assuming the trend of the rapid growth of ETFs on social indices will continue, this is a limitation that will fade in time thus making the social index effect worthwhile for scholars and practitioners to revisit. In addition, it would be interesting for researchers to investigate if there is variability in the financial effects of deletions of firms from social indices according to the particular kind of controversy that led to the deletion. For example, it may be that deletions associated with environmental transgressions are more heavily penalised by the market compared to deletions connected with corporate governance issues (or vice-versa). Relatedly, our use of the Calvert social index and the MSCI KLD 400 index limits our inferences to the context of US firms. Looking at social indices that include firms from different countries would aid in identifying whether the asymmetric social index effect holds in general or varies in terms of magnitude. 


\section{References}

Arnott R. and Vincent S. (1986). "S\&P Additions and Deletions: A Market Anomaly". Journal of Portfolio Management 13 (1), 29-33.

Baumeister R., Bratslavsky E., Finkenauer Vohs and Kathleen D. (2001). "Bad is Stronger than Good". Review of general psychology 5(4), 323.

Becchetti L., Ciciretti R. and Hasan I. (2009). "Corporate Social Responsibility and Shareholder's Value: an Empirical Analysis". Bank of Finland Research Discussion Papers 2009-1.

Beneish M. and Whaley R. (1996). "An Anatomy of the "S\&P Game": The Effects of Changing the Rules". Journal of Finance 51 (5), 1909-1930.

Brown, B. and S. Perry (1994). "Removing the Financial Performance Halo from Fortune's "Most Admired" Companies." Academy of Management Journal 37 (5) 1347-1359.

Brown S. and Warner J. (1985). "Using Daily Stock Returns: The Case of Event Studies". Journal of Financial Economics 14, 3-31.

Brooks C., Kappou K. and W.R. Ward C. (2008). "A Re-examination of the Index Effect: Gambling on Additions to and Deletions from the S\&P500's Gold Seal". Research in International Business and Finance 22, (3), 325-350.

Brooks C, Kappou K. and W.R. Ward C. (2010). "The S\&P 500 Index Effect Reconsidered: Evidence from Overnight and Intraday Stock Price Performance and Volume". Journal of Banking and Finance 34, (1), 116-126.

Campbell J. Y., Lo A. W. MacKinlay A.C. (1997), The Econometrics of Financial Markets, Princeton University Press, Princeton, New Jersey.

Carhart, M. M. (1997). "On Persistence in Mutual Fund Performance." Journal of Finance 52(1), $57-82$

Chen H., Noronha G. and Singal V. (2004). "The Price Response to the S\&P 500 Additions and Deletions: Evidence of Asymmetry and a New Explanation". Journal of Finance 59 (4), 1901-1929.

Chow G., Durand R. and Koh S. (2009). "Are Ethical Investments Good?". University of Western Australia working paper series.

Copeland T. and Mayers D. (1982). "The Value Line Enigma (1965-1978): A Case Study of Performance Evaluation Issues". Journal of Financial Economics 10, 289-321.

Denis D., McConnell J., Ovtchinnikov A. and Yu Y. (2003). "S\&P 500 Index Additions and Earnings Expectations". Journal of Finance 58 (5), 1821-1840

Dhillon U. and Johnson H. (1991). "Changes in the Standard and Poor's 500 List". Journal of Business 64 (1), 75-85 
Doh J., Howton S.D., Howton S.W. and Siegel D. "Does the Market Respond to an Endorsement of Social Responsibility? The Role of Institutions, Information, and Legitimacy". Journal of Management 36 (6), 1461-1485.

Edmister R., Graham S. and Pirie W. (1994). "Excess Returns of Index Replacement Stocks: Evidence of Liquidity and Substitutability". Journal of Financial Research 17 (3), 333-346.

Edmister R., Graham S. and Pirie W. (1996). "Trading Cost Expectations: Evidence from S\&P 500 Index Replacement Stock Announcements". Journal of Economics and Finance 20 (2), 75-85.

Fama E. (1970). "Efficient Capital Markets: A Review of Theory and Empirical Work". Journal of Finance 25 (2), 383-417.

Fama, E. and French K. (1992). "The Cross-section of Expected Stock Returns." Journal of Finance 47(2): 427-465.

Harris L. and Gurel E. (1986). "Price and Volume Effects Associated with Changes in the S\&P 500 List: New Evidence for the Existence of Price Pressures". Journal of Finance 41 (4), 815-829.

Hegde S. and McDernott J. (2003). "The Liquidity Effects of Revisions to the S\&P 500 Index: An Empirical Analysis". Journal of Financial Markets 6, 413-459.

Jain P. (1987). "The Effect on Stock Price of Inclusion or Exclusion from the S\&P 500". Financial Analysts Journal 43 (1), 58-65.

Lamoureux C. and Wansley J. (1987). "Market Effects of Changes in the Standard and Poor's 500 Index". The Financial Review 22 (1), 53- 69.

Lankoski, L. (2009). "Differential Economic Impacts of Corporate Responsibility Issues." Business \& Society 48(2): 206-224.

Malkiel B. and Radisich A. (2001). "The Growth of Index Funds and the Pricing of Equity Securities". Journal of Portfolio Management 27 (2), 9 - 21.

Margolis, J., Elfenbein H. and J.P. Walsh (2009). "Does it Pay to be Good... and Does it Matter? A Meta-analysis of the Relationship between Corporate Social and Financial Performance." Harvard Business School Working Paper No229.

Margolis, J. D. and J. P. Walsh (2003). "Misery Loves Companies: Rethinking Social Initiatives by Business." Administrative Science Quarterly 48 (2), 268-305.

Meijer, M. M. and T. Schuyt (2005). "Corporate Social Performance as a Bottom Line for Consumers." Business \& Society 44(4), 442.

Merton R. (1987). "Presidential Address: A Simple Model of Capital Market Equilibrium with Incomplete Information". Journal of Finance 42 (3), 483-510.

Morck R. and Yang F. (2002). "The Mysterious Growing Value of S\&P 500 Membership". NBER Working Paper No. w8654. 
Oikonomou, I., Brooks, C. and Pavelin, S. (2012), "The Impact of Corporate Social Performance on Financial Risk and Utility: A Longitudinal Analysis". Financial Management, 41 (2), 483-515.

Orlitzky, M., Schmidt F. and Rynes S. (2003). "Corporate Social and Financial Performance: A Meta-analysis." Organization Studies 24(3), 403-441.

Renneboog, L., Ter Horst J. and Zhang C. (2008). "Socially Responsible Investments: Institutional Aspects, Performance, and Investor Behavior." Journal of Banking \& Finance 32(9), $1723-1742$.

Scholes M. (1972). "The Market for Securities: Substitution Versus Price Pressure and the Effects of Information on Share Prices". Journal of Business 45 (2), 179-211.

Schröder, Michael (2007), "Is There a Difference? The Performance Characteristics of SRI Equity Indices." Journal of Business Finance and Accounting 34 (2), 331-348.

Shleifer A. (1986). "Do Demand Curves for Stocks Slope Down?". Journal of Finance 41 (3), 579590 .

Statman M. (2006). "Socially Responsible Indexes". Journal of Porffolio Management 32 (3), 100-109.

Tversky, A. and Kahneman D. (1991). "Loss Aversion in Riskless Choice: A Referencedependent Model." The Quarterly Journal of Economics 106(4), 1039-1061.

Waddock, S. and Graves S. (1997). "The Corporate Social Performance-Financial Performance Link." Strategic Management Journal 18(4): 303-319.

Wood, D. and Jones R. (1995). "Stakeholder Mismatching: A Theoretical Problem in Empirical Research on Corporate Social Performance." International Journal of Organizational Analysis 3(3), 229-267.

Woolridge R. and Ghosh C. (1986). "Institutional Trading and Security Prices: The Case of Changes in the Composition of the S\&P 500 Index". Journal of Financial Research 9 (1), 13- 24.

Wurgler J. and Zhuravskaya E. (2002). "Does Arbitrage Flatten Demand Curves for Stocks?" Journal of Business 75 (4), 583-608. 
Table I: Short run Abnormal Return Performance of Stocks Added to and Deleted from the Calvert social index

\begin{tabular}{|c|c|c|c|c|c|c|}
\hline \multirow[b]{2}{*}{ Day } & \multicolumn{2}{|c|}{ Additions Sample } & \multicolumn{3}{|c|}{ Deletions Sample } & \multirow[b]{2}{*}{$\begin{array}{l}\mathrm{N} \text { of } \\
\text { firms }\end{array}$} \\
\hline & $\begin{array}{l}\text { Abn. } \\
\text { Ret. }\end{array}$ & $\mathrm{t}$-statistic & $\begin{array}{c}\mathrm{N} \text { of } \\
\text { firms }\end{array}$ & Abn. Ret. & t-statistic & \\
\hline $\begin{array}{l}\text { T-10 } \\
\end{array}$ & $0.32 \%$ & 1.77 & 362 & $0.45 \%$ & "1.40 & 179 \\
\hline T-9 & $-0.21 \%$ & -1.16 & 364 & $0.03 \%$ & 0.08 & 178 \\
\hline T-8 & $-0.15 \%$ & -0.81 & 364 & $0.19 \%$ & 0.58 & 177 \\
\hline $\mathrm{T}-7$ & $-0.28 \%$ & -1.53 & 365 & $0.09 \%$ & 0.26 & 178 \\
\hline T-6 & $0.33 \%$ & 1.83 & 365 & $-0.19 \%$ & -0.59 & 177 \\
\hline T-5 & $-0.37 \%$ & -2.04 & 365 & $-0.38 \%$ & -1.16 & 179 \\
\hline $\mathrm{T}-4$ & $0.18 \%$ & 1.01 & 364 & $0.09 \%$ & 0.28 & 177 \\
\hline T-3 & $0.29 \%$ & 1.60 & 365 & $0.45 \%$ & 1.39 & 178 \\
\hline T-2 & $0.10 \%$ & 0.54 & 364 & $-0.88 \%$ & -2.72 & 177 \\
\hline T-1 & $0.07 \%$ & 0.41 & 365 & $0.66 \%$ & 2.05 & 178 \\
\hline$T$ & $-0.15 \%$ & -0.84 & 365 & $0.19 \%$ & 0.58 & 174 \\
\hline$T+1$ & $-0.16 \%$ & -0.90 & 364 & $-0.79 \%$ & -2.45 & 176 \\
\hline$T+2$ & $0.32 \%$ & 1.76 & 365 & $-0.33 \%$ & -1.01 & 178 \\
\hline$T+3$ & $0.13 \%$ & 0.72 & 365 & $0.12 \%$ & 0.36 & 177 \\
\hline$T+4$ & $-0.02 \%$ & -0.12 & 365 & $0.08 \%$ & 0.24 & 176 \\
\hline$T+5$ & $-0.41 \%$ & -2.29 & 365 & $-0.93 \%$ & -2.88 & 178 \\
\hline$T+6$ & $-0.49 \%$ & -2.70 & 365 & $-1.06 \%$ & -3.26 & 179 \\
\hline $\mathrm{T}+7$ & $0.66 \%$ & 3.64 & 365 & $1.24 \%$ & 3.82 & 175 \\
\hline$T+8$ & $-0.17 \%$ & -0.95 & 365 & $-1.03 \%$ & -3.20 & 176 \\
\hline$T+9$ & $-0.26 \%$ & -1.45 & 365 & $-0.73 \%$ & -2.26 & 176 \\
\hline $\mathrm{T}+10$ & $-0.40 \%$ & -2.20 & 364 & $0.18 \%$ & 0.55 & 179 \\
\hline $\mathrm{T}+11$ & $-0.32 \%$ & -1.76 & 364 & $0.12 \%$ & 0.38 & 179 \\
\hline $\mathrm{T}+12$ & $0.04 \%$ & 0.21 & 365 & $1.15 \%$ & 3.56 & 179 \\
\hline $\mathrm{T}+13$ & $-0.17 \%$ & -0.93 & 365 & $0.11 \%$ & 0.34 & 179 \\
\hline $\mathrm{T}+14$ & $0.27 \%$ & 1.52 & 365 & $-0.60 \%$ & -1.86 & 177 \\
\hline $\mathrm{T}+15$ & $0.24 \%$ & 1.33 & 365 & $0.98 \%$ & 3.04 & 175 \\
\hline
\end{tabular}

Note: Day indicates each key date of the event window with event date at time $\mathrm{T}$ as a point of reference. Abnormal returns are defined as the average of the differences between raw returns and market model returns for each date of the event window. T-statistic is the standard t-test measuring the significance of abnormal returns during each date of the event period, with bold numbers indicating significance at $5 \%$ level or better. $N$ represents the number of firms in the sample. 
Table II: Short run Abnormal Return Performance of Stocks Added to and Deleted from the MSCI KLD 400 social index

\begin{tabular}{|c|c|c|c|c|c|c|}
\hline & Additic & Sample & & Deletions & Sample & \\
\hline Day & $\begin{array}{l}\text { Abn. } \\
\text { Ret. }\end{array}$ & t-statistic & $\begin{array}{l}\mathrm{N} \text { of } \\
\text { firms }\end{array}$ & Abn. Ret. & t-statistic & $\begin{array}{l}\mathrm{N} \text { of } \\
\text { firms }\end{array}$ \\
\hline T-10 & $-0.10 \%$ & -0.64 & 201 & $0.29 \%$ & 0.85 & 77 \\
\hline T-9 & $0.11 \%$ & 0.65 & 201 & $0.40 \%$ & 1.17 & 77 \\
\hline T-8 & $0.16 \%$ & 0.95 & 202 & $-0.15 \%$ & -0.44 & 78 \\
\hline T-7 & $0.18 \%$ & 1.11 & 201 & $-0.16 \%$ & -0.47 & 78 \\
\hline T-6 & $-0.01 \%$ & -0.04 & 202 & $-0.17 \%$ & -0.50 & 75 \\
\hline$T-5$ & $-0.17 \%$ & -1.04 & 201 & $0.03 \%$ & 0.08 & 74 \\
\hline T-4 & $0.05 \%$ & 0.32 & 202 & $0.29 \%$ & 0.86 & 78 \\
\hline T-3 & $0.11 \%$ & 0.66 & 202 & $0.53 \%$ & 1.55 & 77 \\
\hline T-2 & $0.19 \%$ & 1.14 & 202 & $0.09 \%$ & 0.26 & 72 \\
\hline T-1 & $0.03 \%$ & 0.17 & 202 & $-0.04 \%$ & -0.11 & 73 \\
\hline$T$ & $0.02 \%$ & 0.14 & 200 & $-0.69 \%$ & -2.02 & 72 \\
\hline $\mathrm{T}+1$ & $0.01 \%$ & 0.09 & 202 & $0.11 \%$ & 0.31 & 76 \\
\hline$T+2$ & $-0.03 \%$ & -0.19 & 202 & $-0.50 \%$ & -1.46 & 73 \\
\hline$T+3$ & $0.00 \%$ & -0.01 & 202 & $-0.38 \%$ & -1.12 & 75 \\
\hline$T+4$ & $0.09 \%$ & 0.52 & 202 & $0.58 \%$ & 1.70 & 75 \\
\hline$T+5$ & $0.16 \%$ & 0.95 & 201 & $-0.16 \%$ & -0.47 & 76 \\
\hline$T+6$ & $-0.32 \%$ & -1.94 & 199 & $0.02 \%$ & 0.06 & 77 \\
\hline $\mathbf{T}+7$ & $-0.27 \%$ & -1.61 & 202 & $-0.09 \%$ & -0.26 & 74 \\
\hline$T+8$ & $-0.11 \%$ & -0.67 & 202 & $-0.30 \%$ & -0.89 & 74 \\
\hline$T+9$ & $-0.28 \%$ & -1.67 & 201 & $-0.40 \%$ & -1.17 & 73 \\
\hline $\mathrm{T}+10$ & $0.18 \%$ & 1.07 & 202 & $-0.23 \%$ & -0.66 & 73 \\
\hline $\mathrm{T}+11$ & $-0.07 \%$ & -0.45 & 201 & $-0.08 \%$ & -0.25 & 77 \\
\hline $\mathrm{T}+12$ & $-0.05 \%$ & -0.33 & 202 & $0.18 \%$ & 0.54 & 78 \\
\hline $\mathrm{T}+13$ & $0.28 \%$ & 1.70 & 202 & $-0.12 \%$ & -0.36 & 77 \\
\hline $\mathrm{T}+14$ & $-0.14 \%$ & -0.84 & 202 & $-0.42 \%$ & -1.24 & 77 \\
\hline$T+15$ & $-0.29 \%$ & -1.74 & 202 & $0.19 \%$ & 0.57 & 77 \\
\hline
\end{tabular}

Note: Day indicates each key date of the event window with event date at time $\mathrm{T}$ as a point of reference. Abnormal returns are defined as the average of the differences between raw returns and market model returns for each date of the event window. T-statistic is the standard t-test measuring the significance of abnormal returns during each date of the event period, with bold numbers indicating significance at $5 \%$ level or better. $N$ represents the number of firms in the sample. 


\begin{tabular}{|c|c|c|c|c|}
\hline \multicolumn{5}{|c|}{$\begin{array}{l}\text { Table III: Cumulative Abnormal Return Performance of Stocks } \\
\text { Added to and Deleted from the Calvert social index }\end{array}$} \\
\hline \multirow[b]{2}{*}{ Window } & \multicolumn{2}{|c|}{ Additions Sample } & \multicolumn{2}{|c|}{ Deletions Sample } \\
\hline & CAARs & t-statistic & CAARs & t-statistic \\
\hline $\mathrm{T}-5$ to $\mathrm{T}-1$ & $0.27 \%$ & 0.68 & $-0.05 \%$ & -0.07 \\
\hline T-3 to $T-1$ & $0.46 \%$ & 1.47 & $0.23 \%$ & 0.42 \\
\hline$T-1$ to $T+1$ & $-0.24 \%$ & -0.76 & $0.06 \%$ & 0.10 \\
\hline T only & $-0.15 \%$ & -0.84 & $0.19 \%$ & 0.58 \\
\hline $\mathrm{T}+1$ to $\mathrm{T}+15$ & $-0.75 \%$ & -1.07 & $-1.49 \%$ & -1.19 \\
\hline$T$ to $T+125$ & $-0.28 \%$ & -0.14 & $-1.39 \%$ & -0.38 \\
\hline
\end{tabular}

Table IV: Cumulative Abnormal Return Performance of Stocks Added to and Deleted from the MSCI KLD 400 social index

\begin{tabular}{lcccc}
\hline \hline & \multicolumn{2}{c}{ Additions Sample } & \multicolumn{2}{c}{ Deletions Sample } \\
\hline Window & CAARs & t-statistic & CAARs & t-statistic \\
\hline \hline T-5 to T-1 & $0.21 \%$ & 0.56 & $0.90 \%$ & 1.18 \\
T-3 to $\mathbf{T}-1$ & $0.32 \%$ & 1.14 & $0.58 \%$ & 0.98 \\
T-1 to $\mathbf{T}+\mathbf{1}$ & $0.07 \%$ & 0.23 & $-0.62 \%$ & -1.05 \\
T only & $0.02 \%$ & 0.14 & $-0.69 \%$ & $-\mathbf{2 . 0 2}$ \\
T+1 to $\mathbf{T}+\mathbf{1 5}$ & $-0.84 \%$ & -1.32 & $-1.61 \%$ & -1.22 \\
T to $\mathbf{T}+\mathbf{1 2 5}$ & $-2.88 \%$ & -1.56 & $-14.00 \%$ & $\mathbf{- 3 . 6 5}$ \\
\hline \hline
\end{tabular}

Note: Window defines the number of days taken into account with event date at time $\mathrm{T}$ as a point of reference. $C A A R$ is the cumulative average abnormal return of the firms for the corresponding window and t-statistic is the standard t-test measuring the significance of the cumulative average abnormal returns for the defined period, with bold numbers indicating significance at $5 \%$ level or better. 
Table V: Effect of Additions to and Deletions from the Calvert index on Trading Volume

\begin{tabular}{|c|c|c|c|c|}
\hline & Additions Sample & & eletions Sample & \\
\hline Day & Volume Ratio & t- statistic & Volume Ratio & t- statistic \\
\hline T-10 & 1.04 & 1.16 & 1.10 & 0.74 \\
\hline T-9 & 1.03 & 1.11 & 0.96 & -0.80 \\
\hline T-8 & 1.00 & 0.04 & 1.05 & 0.59 \\
\hline $\mathrm{T}-7$ & 1.01 & 0.41 & 1.06 & 1.02 \\
\hline T-6 & 1.03 & 1.01 & 1.19 & 1.67 \\
\hline T-5 & 1.02 & 0.62 & 1.01 & 0.21 \\
\hline $\mathrm{T}-4$ & 0.99 & -0.27 & 1.05 & 0.87 \\
\hline T-3 & 0.99 & -0.14 & 0.98 & -0.38 \\
\hline $\mathrm{T}-2$ & 1.00 & 0.08 & 0.95 & -1.06 \\
\hline T-1 & 1.06 & 1.18 & 1.06 & 0.77 \\
\hline $\mathbf{T}$ & 1.32 & 1.37 & 1.33 & 0.91 \\
\hline $\mathbf{T}+1$ & 1.33 & 1.19 & 1.47 & 1.08 \\
\hline $\mathbf{T}+2$ & 1.43 & 1.17 & 1.61 & 1.00 \\
\hline$T+3$ & 1.36 & 1.17 & 1.53 & 1.06 \\
\hline$T+4$ & 1.43 & 1.28 & 1.61 & 1.11 \\
\hline$T+5$ & 1.85 & 1.15 & 2.27 & 1.04 \\
\hline$T+6$ & 1.56 & 1.23 & 1.76 & 1.04 \\
\hline $\mathbf{T}+7$ & 1.35 & 1.41 & 1.35 & 0.86 \\
\hline$T+8$ & 1.44 & 1.31 & 1.48 & 0.86 \\
\hline$T+9$ & 1.09 & 2.04 & 0.93 & -1.70 \\
\hline $\mathrm{T}+10$ & 1.35 & 1.34 & 1.39 & 0.89 \\
\hline $\mathrm{T}+11$ & 1.59 & 1.19 & 1.74 & 0.91 \\
\hline $\mathrm{T}+12$ & 1.31 & 1.36 & 1.35 & 0.94 \\
\hline$T+13$ & 1.34 & 1.43 & 1.39 & 1.01 \\
\hline $\mathrm{T}+14$ & 1.40 & 1.54 & 1.34 & 0.81 \\
\hline$T+15$ & 1.26 & 1.32 & 1.45 & 1.24 \\
\hline
\end{tabular}

Note: Day indicates each key date of the event window with event date at time $\mathrm{T}$ as a point of reference. Volume Ratio is the average volume ratio over the base volume ratio (estimated over 60 days before the event period) for each day of the event window. T-statistic is the standard t-test measuring the significance of the average volume ratios each day of the event period, with bold numbers indicating significance at $5 \%$ level or better. 


\begin{tabular}{|c|c|c|c|c|}
\hline & Additions Sample & & etions Sample & \\
\hline Day & Volume Ratio & t- statistic & Volume Ratio & t- statistic \\
\hline T-10 & 1.01 & 0.20 & 1.61 & 2.93 \\
\hline T-9 & 1.05 & 0.78 & 1.35 & 2.57 \\
\hline T-8 & 1.05 & 1.00 & 1.59 & 2.19 \\
\hline $\mathrm{T}-7$ & 1.06 & 1.33 & 1.38 & 2.17 \\
\hline T-6 & 1.09 & 1.25 & 1.67 & 2.65 \\
\hline T-5 & 1.23 & 1.56 & 1.69 & 2.27 \\
\hline T-4 & 1.07 & 1.36 & 1.78 & 2.68 \\
\hline T-3 & 1.10 & 1.61 & 1.43 & 2.86 \\
\hline T-2 & 1.05 & 0.94 & 1.82 & 3.44 \\
\hline T-1 & 1.10 & 1.40 & 2.72 & 2.87 \\
\hline $\mathbf{T}$ & 1.83 & 1.66 & 4.48 & 2.67 \\
\hline$T+1$ & 1.75 & 1.19 & 4.06 & 1.95 \\
\hline $\mathbf{T}+2$ & 1.43 & 1.31 & 2.89 & 2.31 \\
\hline $\mathbf{T}+3$ & 1.24 & 1.36 & 2.22 & 2.29 \\
\hline$T+4$ & 1.31 & 1.63 & 1.91 & 1.99 \\
\hline$T+5$ & 1.28 & 1.47 & 1.96 & 2.08 \\
\hline$T+6$ & 1.29 & 1.26 & 1.76 & 1.49 \\
\hline $\mathbf{T}+7$ & 1.33 & 1.34 & 1.81 & 1.49 \\
\hline$T+8$ & 1.05 & 0.74 & 1.22 & 1.64 \\
\hline $\mathbf{T}+9$ & 1.28 & 1.24 & 2.06 & 1.91 \\
\hline $\mathrm{T}+10$ & 1.22 & 1.53 & 1.74 & 2.19 \\
\hline $\mathrm{T}+11$ & 1.36 & 1.96 & 1.72 & 1.85 \\
\hline $\mathrm{T}+12$ & 1.12 & 1.12 & 1.39 & 1.56 \\
\hline $\mathrm{T}+13$ & 1.18 & 1.19 & 1.67 & 1.80 \\
\hline $\mathrm{T}+14$ & 1.16 & 1.25 & 1.35 & 1.21 \\
\hline$T+15$ & 1.17 & 1.24 & 1.31 & 1.11 \\
\hline
\end{tabular}

Note: Day indicates each key date of the event window with event date at time $\mathrm{T}$ as a point of reference. Volume Ratio is the average volume ratio over the base volume ratio (estimated over 60 days before the event period) for each day of the event window. T-statistic is the standard t-test measuring the significance of the average volume ratios each day of the event period, with bold numbers indicating significance at $5 \%$ level or better. 


\begin{tabular}{lcccc}
\hline \multicolumn{4}{l}{ Table VII: Pre-event and post-event Earnings per Share for Calvert index member stocks } \\
\hline \hline & Additions Sample & \multicolumn{3}{c}{ Deletions Sample } \\
\hline \multirow{2}{*}{ Ere-event period } & 2.24 & St. Error & EPS mean & St. Error \\
post-event period & 2.59 & 0.44 & 1.39 & 0.30 \\
$\Delta($ EPS $\%$ & $15.60 \%$ & & 1.09 & 0.21 \\
equality of means t-statistic & 0.53 & & $-21.20 \%$ & \\
& & & 0.81 & \\
\hline
\end{tabular}

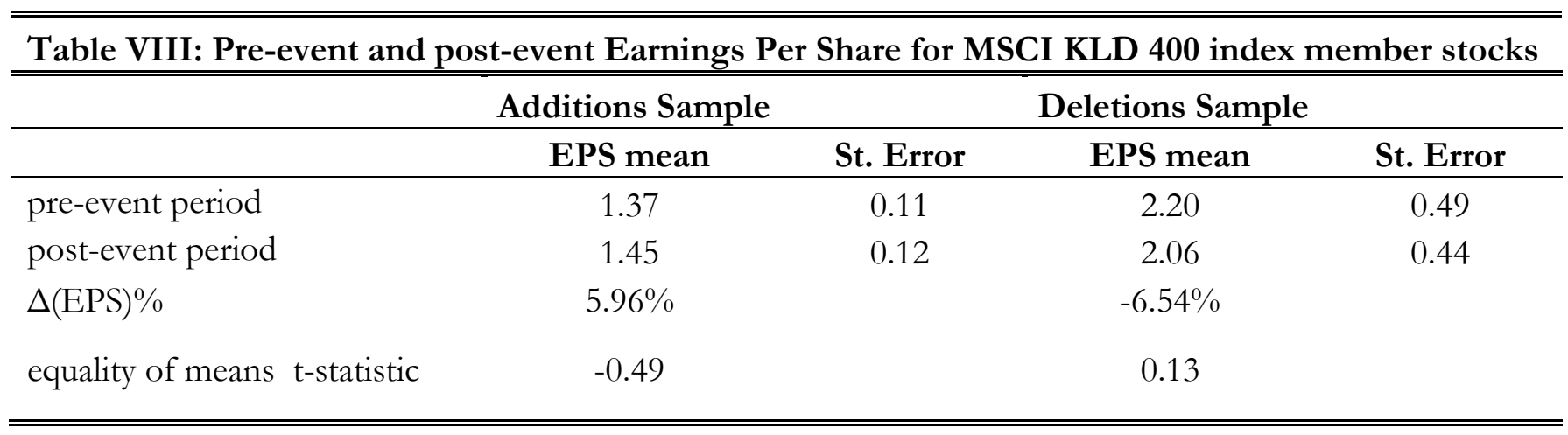

Note: Pre-event and post-event periods refer to one year before and one year after the event date for each firm, respectively. EPS mean measures the average earnings per share for each firm a year before and a year after the event (earnings are announced quarterly and are averaged over four calendar quarters). Standard Error of the EPS mean measures the standard deviation of the mean. T-statistic refers to the test of the equality of EPS means before and after the event. 
Figure 1: Cumulative performance after addition to the Calvert index according to firm size

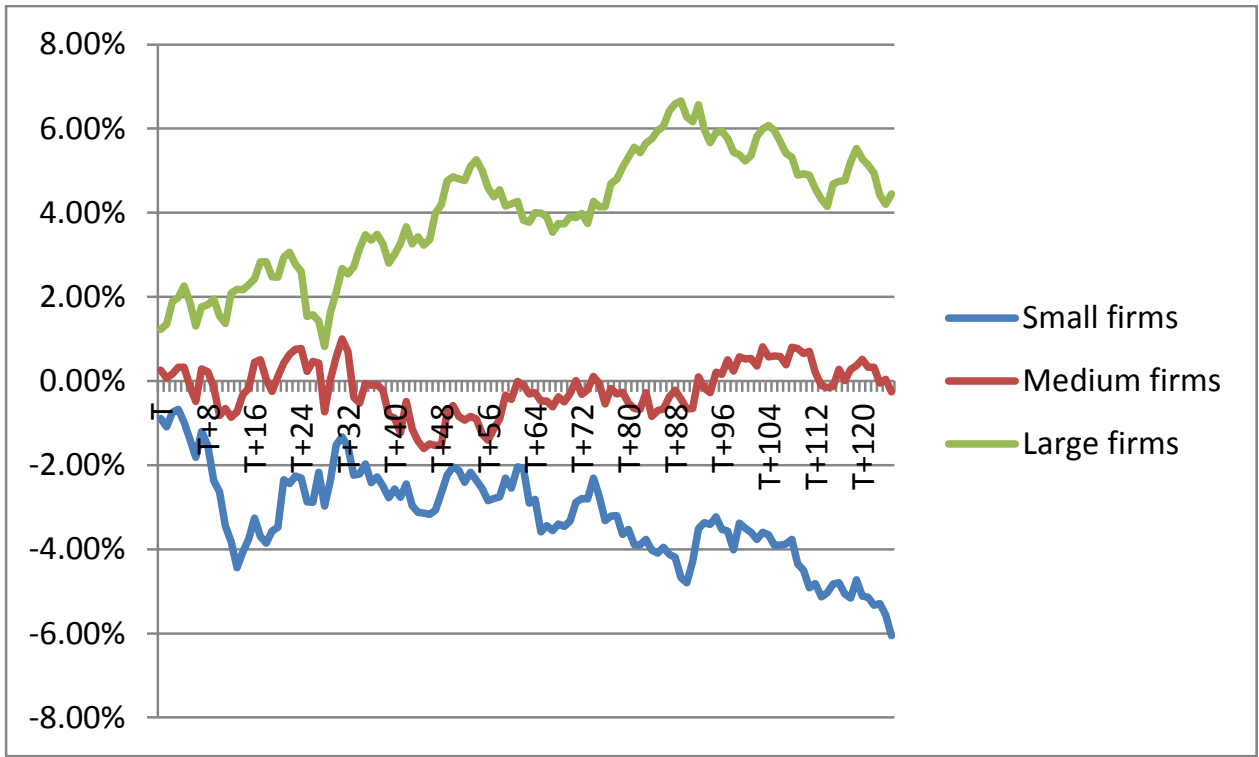

Figure 2: Cumulative performance after deletion to the MSCI KLD 400 index according to firm size

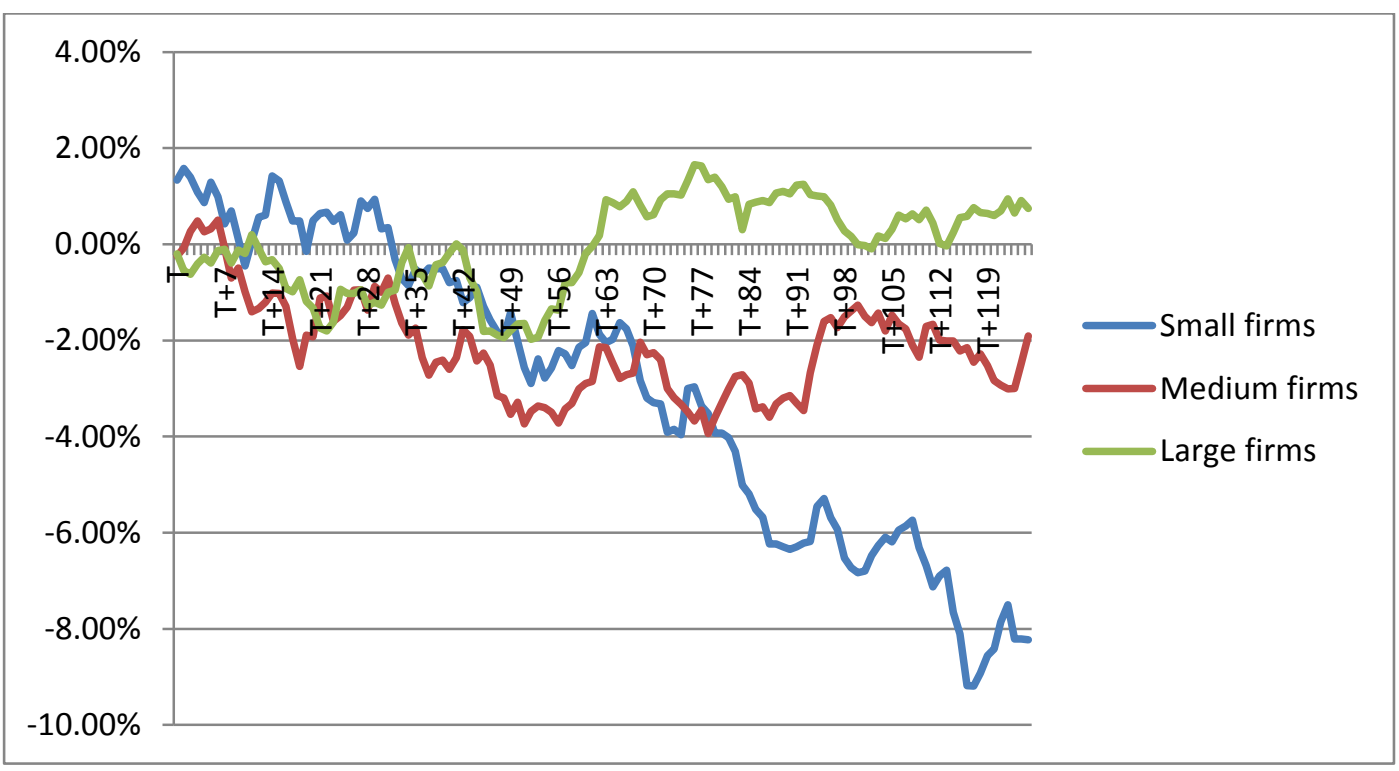


Figure 3: Long run Trading Volume Performance after Addition to the Calvert Index

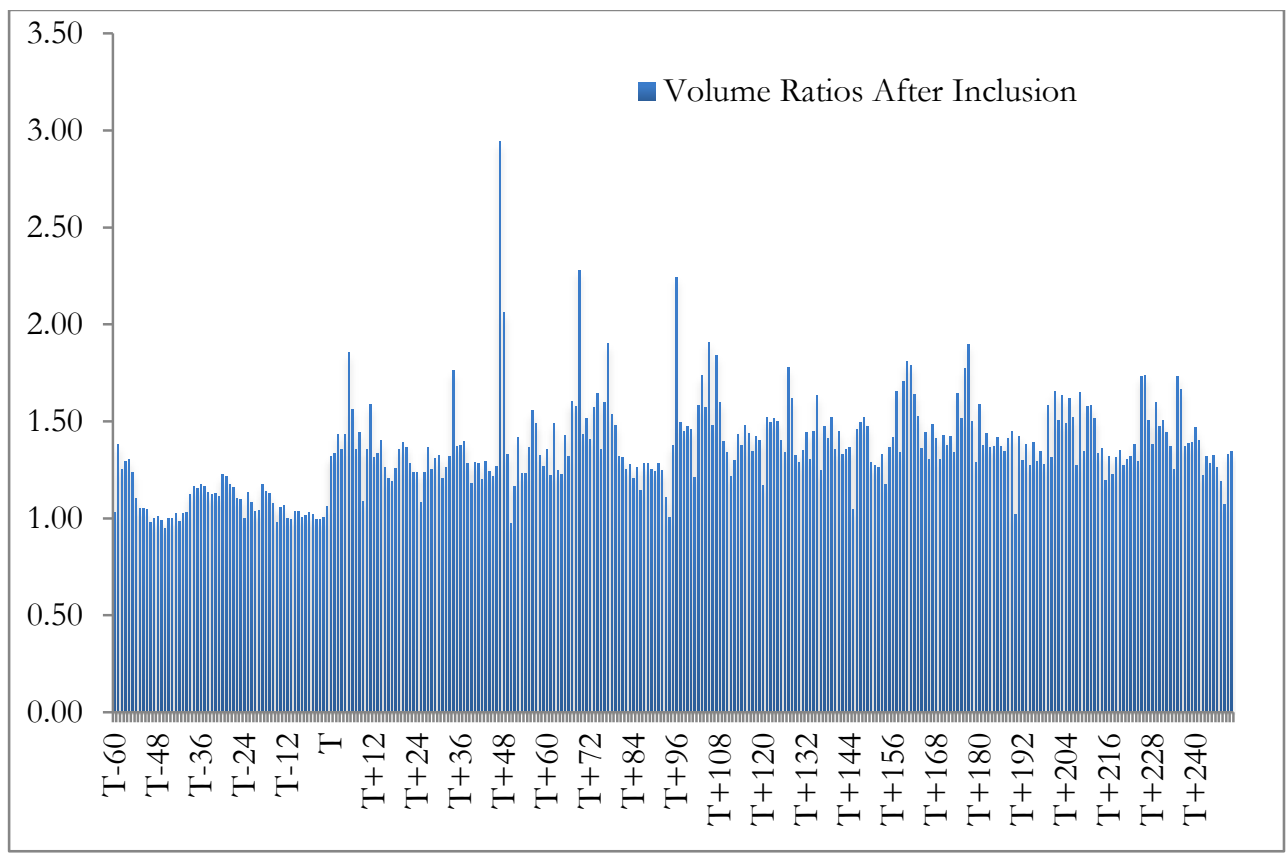

Figure 4: Long run Trading Volume Performance after Deletion from the Calvert Index

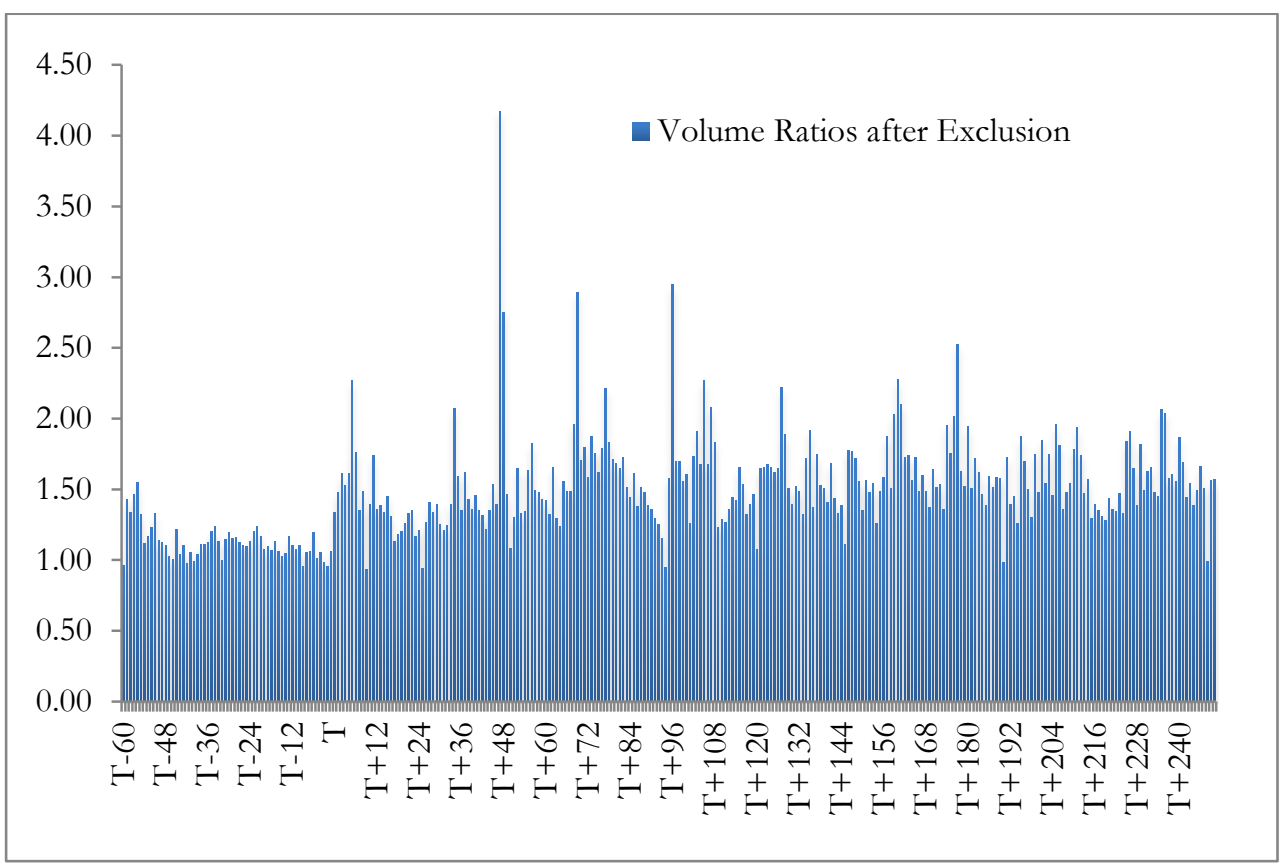


Figure 5: Long Term Trading Volume Performance after Addition to the MSCI KLD 400 index

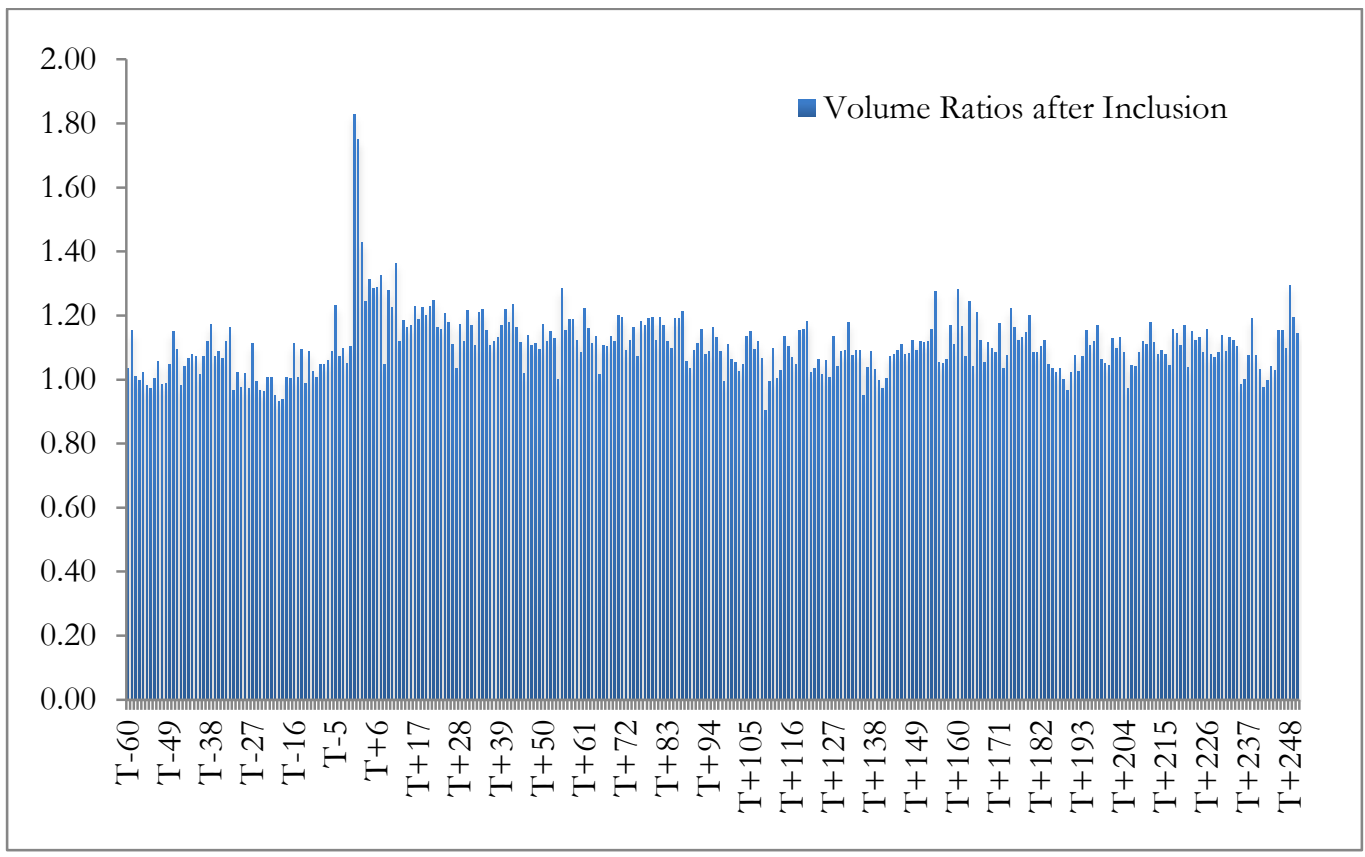

Figure 6: Long Term Trading Volume Performance after Deletion from the MSCI KLD 400 index

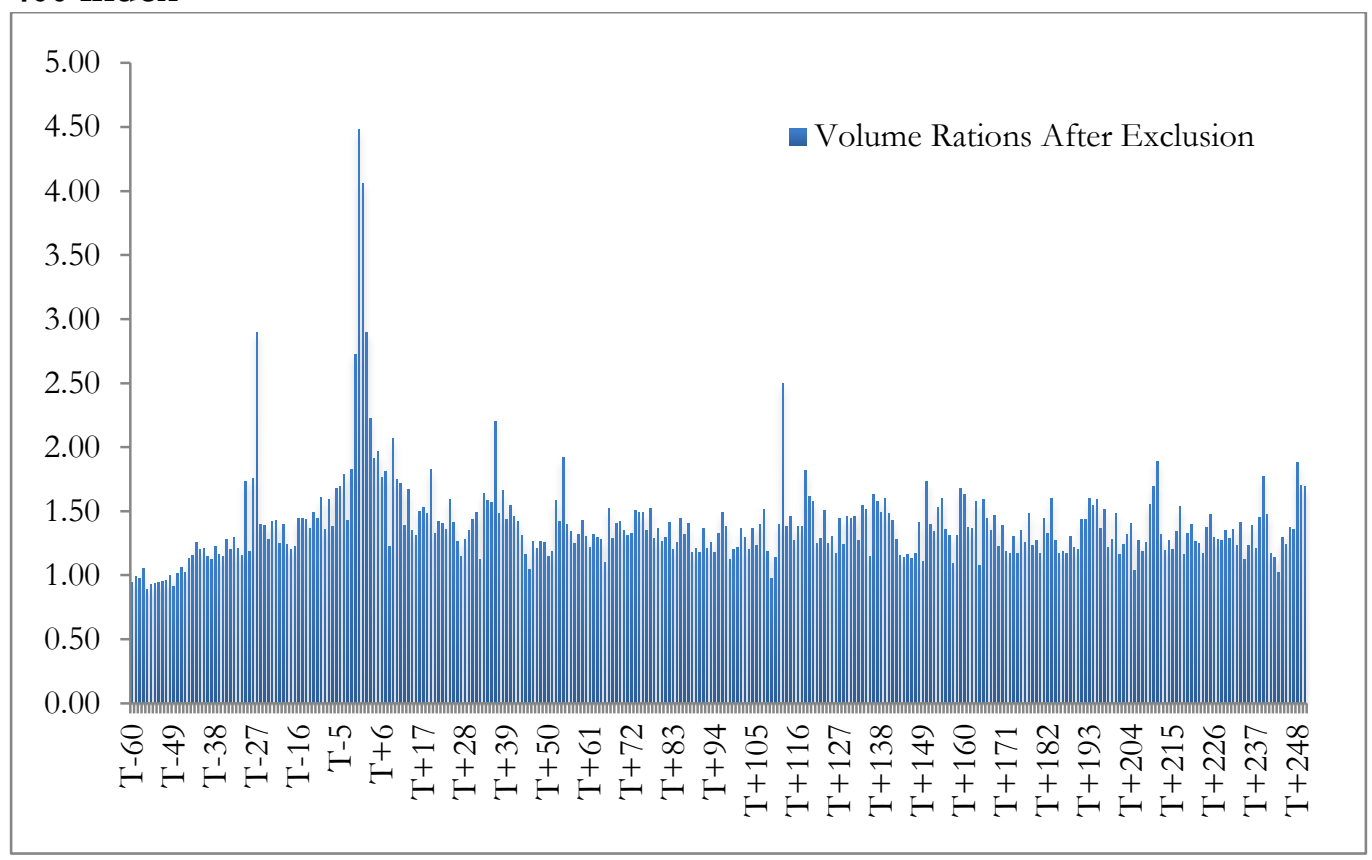




\section{Appendix}

\section{ESG criteria for the MSCI KLD 400 index}

MSCI's ESG research framework generates an analysis and rating of each company's management of its environmental, social and governance performance. The rating criteria address a company's ESG performance in the context of five categories, covering key corporate stakeholders.

- Environment - rate a company's management of its environmental challenges, including its effort to reduce or offset the impacts of its products and operations.

- Community and Society - measure how well a company manages its impact on the communities where it operates, including its treatment of local population, its handling of human rights issues and its commitment to philanthropic activities.

- Employees and Supply Chain - assess a company's record of managing employees, contractors and suppliers. Issues of particular interest include labor-management relations, antidiscrimination policies and practices, employee safety, and the labor rights of workers throughout the company's supply chain.

- Customers - measure the quality and safety record of a company's products, its marketing practices, and any involvement in regulatory or anti-competitive controversies.

- Governance and Ethics - address a company's investor relations and management practices, including company sustainability reporting, board accountability and business ethics policies and practices.

MSCI applies its proprietary ESG rating framework to each company by selecting the ESG rating criteria most relevant to each firm. To evaluate a company, analysts review more than 500 data points and score more than 100 indicators. MSCI expresses a company's ESG performance as a numerical score and on a letter-based rating scale. The ratings fall on a nine-point scale from AAA to $C$. Scores and ratings are not normalized across individual industries or the overall company universe. This means that one industry may have no companies that receive any " $\mathrm{A}$ " ratings, while another industry may have no companies with "C" ratings. In addition, the index excludes companies with significant business activities involving alcohol, tobacco, firearms, gambling, nuclear power or military weapons. ${ }^{13}$

13 All information comes from MSCI KLD 400 Social Index Methodology, May 2011. 


\section{ESG criteria for the Calvert social index}

Calvert's Social Research Department conducts a social audit in the following areas: Products, Environment, Workplace, Integrity. The stocks that meet Calvert's social criteria make up the Calvert social index. More specifically:

- Products: Are the company's products safe, useful and beneficial? Does the company produce firearms, tobacco, alcohol, pornography, casino games or military weaponry?

- Environment: Is the company in compliance with government regulations? Is it working to reduce its impact on the environment?

- Workplace: How does the company rate on labor relations? Does it treat employees fairly, offer reasonable benefits, and provide a safe workplace?

- Integrity: Does the company have good community relations? If it's a bank, does it provide credit without discriminating against people in its service area? If it's a natural resources extractor, do they deal fairly with indigenous people? Companies with overseas operations, such as footwear and apparel manufacturers, are included as well.

Calvert's Social Research Department analyzes each company in each criteria area with its proprietary social research methodology, using:

- In-house files on almost 7,000 companies. Calvert gathers information using the LexisNexis database, the world's largest news and business information service. Calvert also subscribes to hundreds of specialty publications, ranging from industry publications to social responsibility reports.

- Conversations with company management. Calvert wants to know what challenges they face and what (if any) innovative programs they have that contribute to best practices within their industry.

- Data from US environmental and social regulatory agencies. For example, analysts can directly link to the Environmental Protection Agency's databases and review a company's environmental performance by factory.

- Discussions with advocacy organizations such as environmental groups, consumer groups, labor unions, and human rights organizations. ${ }^{14}$

In addition, Calvert avoids including companies with interests in gambling, tobacco, alcohol, firearms, and nuclear power to the index. ${ }^{15}$

\footnotetext{
${ }^{14}$ All information comes from http://www.calvert.com/sri-index-faq.html, last accessed May 25 ${ }^{\text {th }}, 2012$.

${ }^{15}$ Information comes from http://www.socialfunds.com/funds/profile.cgi?sfFundId=574, last accessed May 25 2012.
} 